ORIGINAL ARTICLE

\title{
The relative importance of whole body vibration and occupational lifting as risk factors for low-back pain
}

\author{
K T Palmer, M J Griffin, H E Syddall, B Pannett, C Cooper, D Coggon
}

Occup Environ Med 2003;60:715-721

See end of article for authors' affiliations .....................

Correspondence to: Dr K T Palmer, MRC Environmental Epidemiology Unit, Southampton General Hospital, Southampton SO16 6YD, UK;

ktp@mrc.soton.ac.uk

Accepted

7 November 2002

\begin{abstract}
Aims: To explore the impact of occupational exposure to whole body vibration (WBV) on low back pain (LBP) in the general population and to estimate the burden of LBP attributable to occupational WBV in comparison with that due to occupational lifting.

Methods: A questionnaire including sections on WBV at work, LBP, and potential risk factors was mailed to a community sample of 22194 men and women of working age. Sources and durations of exposure to occupational WBV were ascertained for the past week and personal vibration doses (eVDV) were estimated. Analysis was confined to subjects reporting exposures in the past week as typical of their work. Associations of LBP with eVDV, driving industrial vehicles, and occupational lifting were explored by logistic regression and attributable numbers were calculated.

Results: Significant associations were found between daily lifting of weights greater than $10 \mathrm{~kg}$ at work and LBP, troublesome LBP (which made it difficult to put on hosiery), and sciatica (prevalence ratios 1.3 to 1.7); but the risk of these outcomes in both sexes varied little by eVDV and only weak associations were found with riding on industrial vehicles. Assuming causal associations, the numbers of cases of LBP in Britain attributable to occupational WBV were estimated to be 444000 in men and 95000 in women. This compared with an estimated 940000 male cases and 370000 female cases of LBP from occupational lifting.

Conclusions: The burden of LBP in Britain from occupational exposure to WBV is smaller than that attributable to lifting at work.
\end{abstract}

W hole body vibration (WBV) is one of the most common occupational hazards in Britain. Recently it has been estimated that 8.5 million men and women are exposed on a weekly basis to occupational sources of WBV, including some 370000 workers with exposures exceeding a proposed British Standard action level of $15 \mathrm{~ms}^{-1.75}$ for the estimated vibration dose value (eVDV). ${ }^{1}$ The action level was prompted by a growing body of evidence that regular vibration and jolting contributes to an excess of low back pain (LBP) in drivers of cars, vans, buses, tractors, and fork lift trucks, crane operators, and helicopter pilots.

This evidence has accrued mainly from studies of WBV and LBP in industrial populations, ${ }^{2-9}$ and relatively few investigations have been based on samples from the wider community. ${ }^{10-14}$ Studies have generally focused on selected occupations suspected to be at special risk, which is an appropriate approach for testing the hypothesis that WBV causes LBP. However, to assess the burden of LBP arising from this cause in the community, and to compare it with that due to other common physical exposures like lifting, information is needed at the population level. This gives a public health perspective on priorities for prevention, taking into account the predominant patterns of exposures that exist nationally.

We have conducted a large postal survey, based on a community sample, to assess patterns of exposure to WBV in Great Britain. ${ }^{1}$ As part of the survey, we also collected information about back symptoms and about occupational lifting. In this paper we report on the occupational burden of LBP attributable to WBV in Britain, and compare it with that related to lifting at work.

\section{METHODS}

In 1997-98 we mailed a questionnaire about exposure to vibration and health to a sample of 22194 men and women aged 16-64 years. These comprised 21201 subjects selected at random from the patient lists of 34 general practices, and 993 members of the armed services randomly selected from central pay records. The practices were chosen to give a broad coverage of Great Britain and to ensure that industries involving known exposure to vibration were adequately sampled. Further details of the method are described elsewhere. ${ }^{115}$

Among other things, the questionnaire asked about employment status and occupation; history of low back symptoms in the past 12 months; smoking habits; height; frequency of headaches and feeling tired or stressed; exposures to WBV, both at work and elsewhere; lifting weights of $10 \mathrm{~kg}$ or more by hand in an average working day; and digging or shovelling in an average working day. ${ }^{16}$ However, almost all subjects who reported digging and shovelling also reported occupational lifting, and so only the lifting variable was considered in the analyses that we describe here.

Exposures to WBV were characterised in detail. Information on current occupational exposure came mainly from a closed question about driving or riding any of a checklist of 26 listed vehicles and machines at work in the past week. The list was assembled following a literature review and extensive consultation with safety experts, vibration specialists, occupational physicians, trades unions, and trade associations. ${ }^{16}$ In addition, an open question was posed about other sources of exposure in this period. Responses to the latter were reviewed independently by a vibration specialist (MG), an occupational hygienist (BP),

Abbreviations: eVDV, estimated vibration dose value; LBP, low back pain; PR, prevalence ratio; WBV, whole body vibration 


\section{Main messages}

- Many industry based investigations have found that low back pain (LBP) is associated with exposure to whole body vibration (WBV) and liffing at work.

- The relative importance of these hazards in causing LBP in Britain as whole cannot be established from these data alone. Attributable numbers depend not only on risks in each hazardous occupation, but also on the prevalence of these occupations in the community and the extent to which exposures in the occupations surveyed are representative of their national counterparts.

- In this survey we sampled from the community, inquiring about occupational exposures to WBV and lifting and about LBP.

- Only weak associations were found between estimated dose of WBV and LBP.

- We estimated nationally that some 444000 cases of LBP in men and 95000 in women may be attributable to occupational WBV, compared with an estimated 940000 male and 370000 female cases from occupational liffing.

and an occupational physician (KP), to assess their relevance and to code them, with any differences resolved by consensus. Information was collected on the durations of such exposures and also the time subjects were exposed to common everyday sources of WBV (cars, vans, buses, coaches, trains, and motorcycles) during leisure and in journeys to and from work in the past week. Estimated personal vibration dose values (daily equivalent vibration magnitude or eVDV) were calculated separately for occupational and leisure time exposures by assigning frequency weighted vibration accelerations ( $a_{w z}$ values) to each category of vehicle or machine from a reference list $\mathrm{t}^{1}$ and then adopting the time dependency proposed in British Standard (BS) 6841, 1987. ${ }^{17}$ The assumed $a_{w z}$ values were found to approximate to median measured values when sample measurements were made on several common sources of exposure in an independent survey ${ }^{18}$; and in a second validation survey the accuracy of self reports on sources and durations of exposure was confirmed by comparing questionnaire responses with direct observation (median ratio of reported to observed exposure time to WBV 1.1 , interquartile range $1.0-1.2) .{ }^{19}$

Low back pain (LBP) was defined as back pain lasting a day or longer during the previous 12 months in an area between the twelfth ribs and the gluteal folds (indicated by means of a diagram). Subjects were asked to exclude pain occurring only during pregnancy, menstruation, or febrile illness. Sciatica was defined as LBP which radiated down the leg to below the knee. Low back pain was classed as "troublesome" if it had made it difficult or impossible to put on socks, stockings, or tights. The questions on back symptoms had been used in an earlier survey, ${ }^{20-22}$ and had been found to provide repeatable information. ${ }^{20}$

Analysis was restricted to subjects who had been at work in the week before completing the questionnaire, who reported their occupational exposure to WBV during that week as typical of the job, and who had worked in their current job for 12 months or longer (to conform with the period over which prevalence of symptoms was ascertained).

All statistical analyses were carried out using STATA, release $5 .^{23}$ Associations of back symptoms with WBV and lifting were examined by logistic regression, and the findings

\section{Policy implications}

- The burden of LBP in Britain from occupational exposure to WBV is smaller than that attributable to lifting at work.

- This needs to be taken into consideration in assessing the national priority for preventive actions in relation to these hazards.

were expressed as prevalence ratios (PRs) with associated $95 \%$ confidence intervals (CIs). These were derived from the corresponding odds ratios according to a formula proposed by Zocchetti and colleagues. ${ }^{24}$

Because of uncertainties about the best way of summating exposures over time, ${ }^{25}$ two different exposure comparisons were made in the analyses:

- Estimated occupational eVDV, with cut points chosen to correspond to a daily average $>8.5 \mathrm{~ms}^{-1.75}$ (the lower boundary of the health guidance caution zone suggested in ISO 2631, $1997^{26}$ and $>15 \mathrm{~ms}^{-1.75}$ (the suggested threshold in BS 6841, $1987^{17}$ ).

- Work involving driving or riding on industrial vehicles (yes versus no), as a simple but potentially robust marker of substantial occupational exposure.

In each case the estimated non-occupational contribution (from cars, vans, buses, trains, and motorcycles) to total $\mathrm{eVDV}^{1}$ was considered as a possible factor of adjustment (in three bands).

Attributable numbers (the numbers of men and women in Britain whose symptoms would be avoided if the excess prevalence associated with a risk factor were eliminated) were calculated from the relevant prevalence ratios and from estimates of the prevalences of the risk factors and symptoms nationally. These last two parameters were derived from prevalence estimates in the study sample, standardised according to the distribution of occupations at the 1991 national census ${ }^{127}$ (see Appendix, available on the OEM website, www.occenvmed.com/supplemental). Confidence intervals for attributable numbers were calculated by a bootstrap method. ${ }^{28}$

\section{RESULTS}

Usable replies were obtained from 12907 (58\%) of the 22194 subjects who were originally selected for study, including 9084 who had been at work in the week before completing the questionnaire. Of these, 1466 had held their job for less than a year, and a further 307 indicated that their occupational exposure to WBV in the past week was not typical. This left 4250 men and 3061 women who were included in the analysis. The relative frequency of occupations in these subjects was similar to that in the 1991 national census, except that the sampling design led to slight over-representation of the defence sector.

Table 1 shows the one year prevalence of back complaints by age and sex in the study sample. Rates of LBP were somewhat higher in men than in women, were lowest below age 25 years, and showed little variation with age above 35 years. In contrast, the prevalence of sciatica and troublesome LBP increased progressively with age, but differences between the sexes were less marked. There was no consistent geographical variation in the frequency of symptoms (data not shown).

In both men and women, the prevalence of back problems tended to increase with stature, with PRs of up to 1.2 for men and 1.3 for women in the tallest compared with the shortest 
Table 1 Prevalence of low back symptoms in the past year by age and sex

\begin{tabular}{|c|c|c|c|c|}
\hline Age & No. of subjects* & $\begin{array}{l}\text { Low back pain } \\
\%\end{array}$ & $\begin{array}{l}\text { Sciatica } \\
\%\end{array}$ & $\begin{array}{l}\text { Troublesome low back } \\
\text { pain } \\
\%\end{array}$ \\
\hline \multicolumn{5}{|l|}{ Men } \\
\hline $16-24$ & 323 & 43.3 & 4.0 & 17.8 \\
\hline $25-34$ & 1039 & 53.7 & 9.6 & 27.6 \\
\hline $35-44$ & 1148 & 54.4 & 13.8 & 34.2 \\
\hline $45-54$ & 1101 & 57.4 & 18.4 & 37.7 \\
\hline $55-65+$ & 592 & 51.2 & 19.7 & 37.6 \\
\hline \multicolumn{5}{|l|}{ Women } \\
\hline $16-24$ & 292 & 34.3 & 3.1 & 14.5 \\
\hline $25-34$ & 737 & 37.7 & 10.3 & 19.0 \\
\hline $35-44$ & 849 & 47.0 & 15.1 & 27.1 \\
\hline $45-54$ & 787 & 47.9 & 18.2 & 32.7 \\
\hline $55-65+$ & 333 & 47.5 & 23.2 & 38.4 \\
\hline
\end{tabular}

fifth of subjects. Back symptoms were also more common among current smokers, especially in men (PRs 1.2 to 1.6). Even stronger associations were found with headaches and feeling tired or stressed. For example, the risk of sciatica was more than doubled in women who said that they frequently felt tired or stressed. Hence, all subsequent analyses were adjusted for these risk factors as well as for age.

Table 2 shows the association of back symptoms with lifting and with occupational eVDV. Risks were significantly increased for all outcomes in subjects who lifted at work, with PRs ranging from 1.3 (for LBP in men) to 1.7 (for sciatica in both sexes and troublesome LBP in women). By contrast, associations of back symptoms with occupational eVDV were weaker, ranging in men from 0.9 to 1.2 with no relation to dose; and in a similar range for women, except that the PR for LBP was significantly increased for eVDV of $8.6-15 \mathrm{~ms}^{-1.75}$ (PR 1.6, 95\% CI 1.2 to 2.0 ).

These estimates relate to subjects who provided complete information on exposure to WBV. Data were incomplete for 566 men and 102 women (either because estimates of the durations of exposure were missing or representative vibration magnitudes could not be assigned with confidence). Among women who reported exposure to WBV but had missing information, risks were modestly but significantly increased for all outcomes (with PRs of 1.3 to 1.4), and among men risk was increased for LBP overall (PR 1.2, 95\% CI 1.1 to 1.3 ) (table 2).

In addition, risk of LBP and sciatica was assessed according to whether or not subjects had driven a heavy industrial vehicle in the past week, with lifting included in the same model (table 3). In male drivers the highest PR was 1.1. In women, the risks were higher, although based on smaller numbers with exposure. The strongest association was with sciatica (PR 1.9, 95\% CI 1.2 to 2.9), but significant associations were also found with LBP overall (PR 1.3) and with troublesome LBP (PR 1.5). In this model, the PRs associated with lifting ranged from 1.3 (95\% CI 1.3 to 1.4 ) for LBP in men to 1.7 (95\% CI 1.5 to 2.0 ) for sciatica, also in men.

The analyses in tables 2 and 3 were repeated with adjustment for non-occupational eVDV, but the estimates of risk were little changed (data not presented). On the basis of the tabulated risks, and assuming causal relations, the number of prevalent cases of LBP nationally attributable to occupational WBV and lifting were estimated (table 4). (Only the exposure metric of eVDV $>0 \mathrm{~ms}^{-1.75}$ was used in this analysis since risk varied little with estimated dose.) The numbers attributable to WBV were estimated to vary in men from -35000 (for sciatica) to 444000 (for LBP); and in women from 7000 to 95000 for these same outcomes. This compared with an estimated 497000 to 940000 male cases and 200000 to 370000 female cases from lifting weights of $\geqslant 10 \mathrm{~kg}$ in an average day at work.

\section{DISCUSSION}

Many industry based investigations have provided evidence on back disorders in subjects exposed to WBV, and increased risks have been reported for a number of exposed occupations, including helicopter pilots, ${ }^{5}$ municipal bus drivers, ${ }^{6}$ commercial travellers, ${ }^{7}$ tractor drivers, ${ }^{29}$ and fork lift truck drivers. $^{3031}$ Similarly, studies in industry have indicated higher risks in jobs that entail significant lifting. ${ }^{32}{ }^{33}$

By contrast, only a few population surveys have examined the risk of LBP from WBV..$^{12-14} 34$ In national terms, the burden of LBP and sciatica attributable to WBV and lifting depends not only on the risks in each hazardous occupation, but also on the prevalence of these occupations in the community. Not all hazardous occupations will necessarily be included in industry based investigations, and the exposures of the populations surveyed may not be representative of those in the same occupations nationally. Therefore, estimation of attributable numbers in the general population requires sampling from the community.

Using this approach, we found only modest excesses of LBP and sciatica with exposure to WBV in men, after allowance for other physical occupational activities, age, and psychological risk factors, and no consistent relation with dose; and the risks were smaller than those associated with lifting. Use of industrial vehicles in general did not appear to confer an increased risk in men. In women, there was evidence of an excess of LBP, sciatica, and troublesome LBP in association with exposure to industrial vehicles in particular, and of LBP with eVDV, but many fewer women had these exposures. The data on WBV do not provide strong evidence to suggest a cause-effect relation (and do not distinguish the risks of sitting and driving from those of merely sitting); but if such a relation is assumed, then in both sexes fewer cases of LBP nationally are estimated to be attributable occupational WBV than to lifting at work.

A few other population surveys provide estimates of risk from WBV. In one such study a crude OR of 2.1 (95\% CI 1.3 to 3.5) was observed for LBP in 2872 Swedish men and women with exposure to WBV..$^{12}$ In a large Canadian study, Liira and colleagues ${ }^{13}$ found that the OR for long term back problems in blue collar workers was 1.8 (95\% CI 1.3 to 2.7$)$ after adjustment for age, sex, and smoking history, but not for physical job demands. Finally, $\mathrm{Xu}$ and colleagues ${ }^{14}$ examined $^{-}$ 


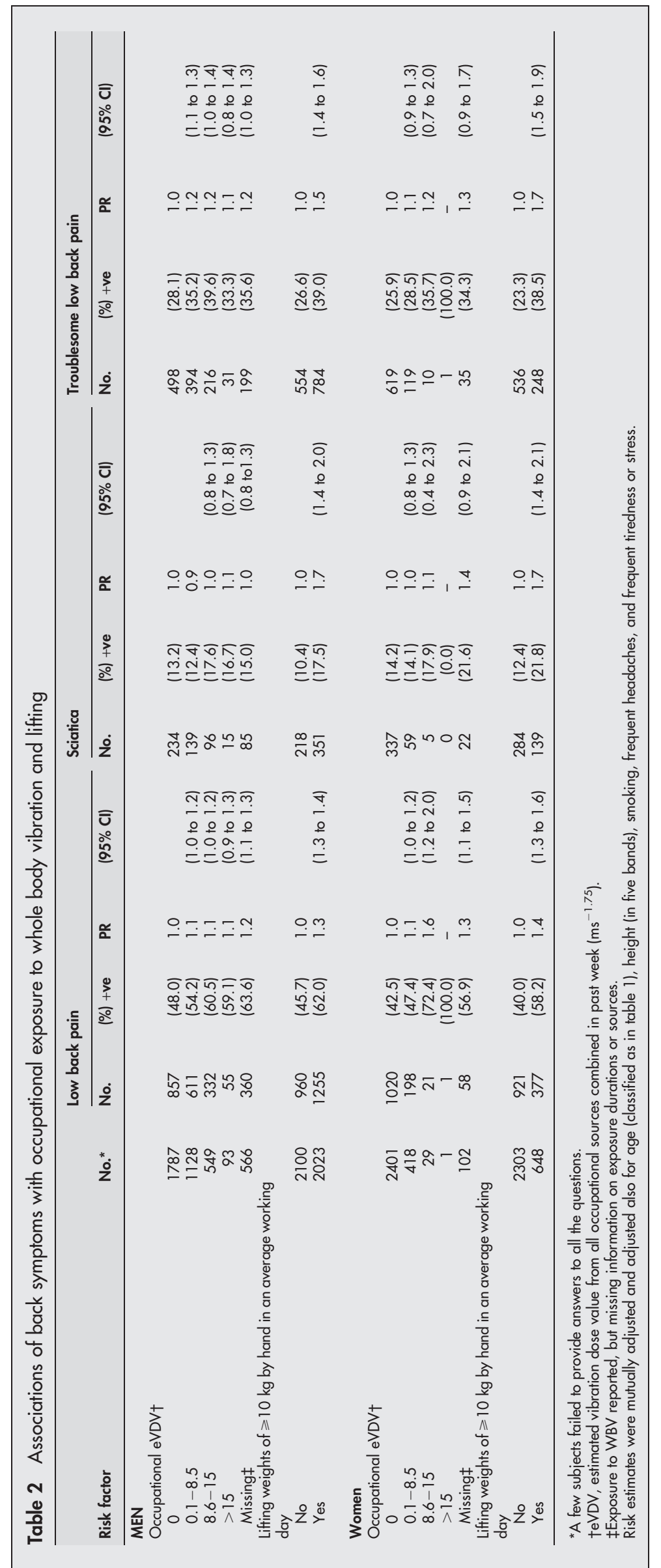




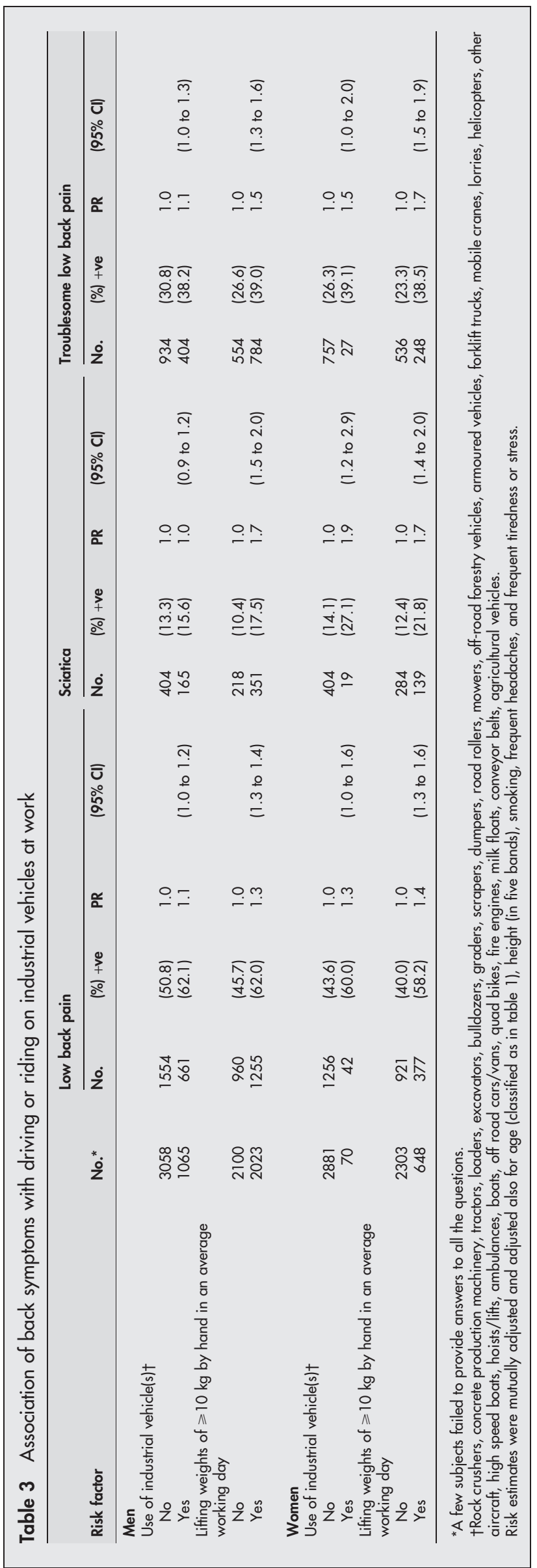

the risks of LBP in 5185 working aged Danish employees. In an analysis which adjusted for arduous physical work, frequent bending or twisting, and heavy lifting, they reported an OR of 1.3 (95\% CI 1.0 to 1.6) for vibration affecting the whole body for more than a quarter of the working time. The last risk estimate is similar to our own, especially when allowance is made for the fact that prevalence ratios are closer to unity than the corresponding odds ratios. Finally, in a population survey from Norrtalje, Sweden, the relative risk (RR) of care seeking for LBP among men who drove for more than six hours per day and had spent $50 \%$ or more of their time driving five years previously was 1.1 (95\% CI 0.6 to 2.5 ) in comparison with those who drove for less than $5 \%$ of the time and were little exposed to other physical risk factors. ${ }^{34}$ As in our survey, higher risks were found for women (RR 2.5, $95 \%$ CI 0.7 to 9.4 ), although women were seldom exposed to this extent.

In general, the risk estimates from population surveys have been lower than those conducted in occupational settings. The discrepancy may be attributable in part to differences in exposure patterns between selected study groups and their counterparts nationally, and in part to uncontrolled confounding in studies that failed to adjust for concomitant exposure to other occupational risk factors such as lifting. (These factors may act in an opposite direction to the "healthy worker" effect commonly observed in cross sectional occupational surveys.) In addition, various other biases may have contributed.

In our own survey it seems unlikely that the lower risk estimates found would be explained by response bias. If anything we would expect people with back pain to have responded more readily if their work involved exposure to a suspected hazard for the disorder, which would lead to higher risk estimates. (In fact, similar prevalences of exposure and outcome were found in those who responded at the first invitation and those who required a reminder.) Similarly, any differential reporting of exposures or symptoms would be expected to inflate rather than depress risk estimates. However, associations could have been weakened by non-differential errors in reporting.

To maximise the accuracy of information on exposure we only asked subjects to recall exposures in the week preceding completion of the questionnaire and restricted our analysis to subjects who considered the past week typical of their exposures at work. Moreover, empirical data from a separate investigation suggest that workers are fairly accurate at reporting their recent sources and durations of exposure to WBV, ${ }^{19}$ and although information on exposure was missing for some subjects, there was no indication that these men and women had an unusually high risk of LBP (table 3). Care was also taken in the construction of the questionnaire and in the coding of open responses to count only relevant exposure sources, and an independent assessment was made of the validity of assumed vibration magnitudes.

Of greater concern, given the cross sectional nature of our investigation and its emphasis on current exposure in employed workers, is the possibility that some of those affected by WBV may have been selected out of employment or to another job. Among current employees who were absent from work in the week preceding completion of the questionnaire ( $3 \%$ of respondents), there was no excess of LBP and no obvious excess of occupations in which exposure to WBV might be expected, but we have no historical information on exposure among unemployed subjects with which to explore possible selection effects. For a major bias from this source, such selection would have to be extensive.

Another possibility is that the association between WBV and LBP was weakened by the choice of exposure metric. The best method of dose summation for WBV is a matter of 
Table 4 Estimated number of cases of low back pain and sciatica attributable to whole body vibration and lifting at work

\begin{tabular}{|c|c|c|c|}
\hline & \multicolumn{3}{|c|}{ Attributable numbers (in thousands) in Great Britain $(95 \% \mathrm{Cl})$} \\
\hline & Low back pain & Sciatica & Troublesome LBP \\
\hline \multicolumn{4}{|l|}{ Men } \\
\hline $\begin{array}{l}\text { Occupational eVDV }>0 \mathrm{~ms}^{-1.75} \\
\text { Liffing weights of } \geqslant 10 \mathrm{~kg}^{\text {by hand }}\end{array}$ & $\begin{array}{l}444(222 \text { to } 666) \\
940 \text { (738 to } 1142)\end{array}$ & $\begin{array}{l}-35(-186 \text { to } 117) \\
497(346 \text { to } 647)\end{array}$ & $\begin{array}{l}423(206 \text { to } 639) \\
797(571 \text { to } 1022)\end{array}$ \\
\hline \multicolumn{4}{|l|}{ Women } \\
\hline $\begin{array}{l}\text { Occupational eVDV }>0 \mathrm{~ms}^{-1.75} \\
\text { Liffing weights of } \geqslant 10 \mathrm{~kg}_{\text {by hand }}\end{array}$ & $\begin{array}{l}95(24 \text { to } 166) \\
370(277 \text { to } 464)\end{array}$ & $\begin{array}{l}7(-44 \text { to } 57) \\
200(113 \text { to } 287)\end{array}$ & $\begin{array}{l}50(-25 \text { to } 124) \\
333(227 \text { to } 439)\end{array}$ \\
\hline
\end{tabular}

eVDV, estimated vibration dose value from all occupational sources combined in past week.

*In an average working day.

The PRs used to derive attributable numbers were mutually adjusted and adjusted also for age (classified as in table 1), height (in five bands), current smoking, frequent headaches, frequent tiredness, or stress. Estimates have been rounded to the nearest hundred. Bootstrapped $95 \% \mathrm{Cls}$ were based on 200 resampling iterations.

debate. ${ }^{25}$ Furthermore, weekly exposure information was available but not daily exposure durations, so an average estimate of dose was made. It was assumed that exposure durations were sufficiently similar on each day of the past week for the average to predict the associated risk, but in practice the relative importance of daily exposure pattern as a risk factor for back pain is not clear. To complete the analysis we therefore considered risk in relation to industrial vehicles, including specific sources previously linked with health complaints. This metric of exposure was crude to the extent that it encompassed exposure to a relevant source whatever its magnitude, but involved fewer assumptions and was likely to have been reported reliably. ${ }^{19}$ However, it did not provide evidence of greater risks, except for a few nationally less common sources of exposure (described elsewhere). ${ }^{35}$

In deriving attributable numbers we have assumed causal relations between the exposures and LBP-although for WBV we found only weak associations with this outcome and no relation to estimated dose. Many of the exposures to WBV that were reported are likely to have been trivial in duration and dose. However, for estimates of population attributable numbers the dilution that arises from inclusion of minor exposures is less likely to cause bias (although it may reduce precision and widen confidence intervals). The calculation also assumes respondents provided representative information on the exposures and risks in their occupational group.

Our data were drawn from a large geographically dispersed sample, but do not necessarily represent the entire range of possible exposures. There may be higher risks in occupational groupings with exceptional levels of exposure that escaped sampling. The data should not therefore be construed as indicating an absence of risk from WBV in highly exposed occupational cohorts. Nevertheless, the findings suggest that the average risk of LBP in individuals from exposure to WBV in Great Britain as a whole is likely to be small, and, assuming causal relations, fewer attributable cases arise from occupational sources of WBV than from lifting at work. This information is of importance in setting national priorities for prevention.

\section{ACKNOWLEDGEMENTS}

This study was supported by a grant from the Health and Safety Executive. We are grateful to the Royal College of General Practitioners, the Primary Care Rheumatology Society, HM Armed Forces, and the 34 general practices that assisted in assembling the mailing lists; the companies that helped in the piloting of the questionnaire; and the staff who were involved in data handling. We are particularly indebted to Ian Bowes and Vanessa Cox for their role in the collection and processing of the data. Paul Brereton and Chris Nelson offered many constructive comments during the course of the study. Denise Gould prepared the manuscript.

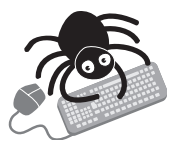

The Appendix is available on the OEM website (www.occenvmed.com/supplemental)

\section{Authors' affiliations}

K T Palmer, H E Syddall, B Pannett, C Cooper, D Coggon, MRC

Environmental Epidemiology Unit, Southampton, UK

M J Griffin, Institute of Sound and Vibration Research, UK

\section{REFERENCES}

1 Palmer KT, Griffin MJ, Bendall H, et al. The prevalence and pattern of occupational exposure to whole-body vibration in Great Britain: findings from a national survey. Occup Environ Med 2000;57:229-36.

2 Hulshof CTJ, Veldhuijzen Van Zenten OB. Whole-body vibration and low back pain - a review of epidemiologic studies. Int Arch Occup Environ Health 1987:59:205-20.

3 Bongers PM, Boshuizen HC, Hulshof CTJ, et al. Back disorders in crane operators exposed to whole-body vibration. Int Arch Occup Environ Health 1988:60:129-37.

4 Bongers PM, Boshuizen HC, Hulshof CTJ, et al. Long-term sickness absence due to back disorders in crane operators exposed to whole-body vibration. Int Arch Occup Environ Health 1988;61:59-64.

5 Bongers PM, Hulshof CTJ, Dijkstra L, et al. Back pain and exposure to whole body vibration in helicopter pilots. Ergonomics 1990;33:1007-26.

6 Bovenzi M, Zadini A. Self-reported low back symptoms in urban bus drivers exposed to whole-body vibration. Spine 1992;17:1048-59.

7 Pietri F, Leclerc A, Boitel L, et al. Low-back pain in commercial drivers. Scand J Work Environ Health 1992; 18:52-8.

8 Burdorf A, Sorock G. Positive and negative risk factors for back disorders. Scand J Work Environ Health 1997;23:243-56.

9 Bovenzi M, Hulsof CTJ. An updated review of epidemiologic studies on the relationship between exposure to whole-body vibration and low back pain Journal of Sound Vibration 1998:215:595-612.

10 Kelsey JL. An epidemiological study of acute herniated lumbar intervertebral discs. Rheumatol Rehab 1975;14:144-58.

11 Kelsey JL, Githens PB, O'Conner T, et al. Acute prolapsed lumbar intervertebral disc: an epidemiological study with special reference to driving automobiles and cigarette smoking. Spine 1984;9:608-13.

12 Saraste H, Hultman G. Life conditions of persons with and without low-back pain. Scand J Rehab Med 1987;19:109-13.

13 Liira JP, Shannon HS, Chambers LW, et al. Long-term back problems and physical work exposures in the 1990 Ontario Health Survey. Am J Public Health 1996:86:382-7.

$14 X_{\mathbf{u}} \mathrm{Y}$, Bach E, Orhede E. Work environment and low back pain: the influence of occupational activities. Occup Environ Med 1997;54:741-5.

15 Palmer KT, Griffin MJ, Bendall H, et al. The prevalence and pattern of occupational exposure to hand-transmitted vibration in Great Britain: findings from a national survey. Occup Environ Med 2000;57:218-28.

16 Palmer K, Coggon D, Pannett B, et al. The development of a self-administered questionnaire to assess exposures to hand-transmitted and whole-body vibration and their health effects. J Sound Vib 1998:215:653-86.

17 British Standards Institution. Measurement and evaluation of human exposure to whole-body mechanical vibration and repeated shock. British Standard BS 6841, 1987.

18 Paddan GS, Haward BM, Griffin MJ, et al. Whole-body vibration: evaluation of some common sources of exposure in Great Britain. Contract Research Report 235/1999. Sudbury: HSE Books, 1999. 
19 Palmer KT, Haward BM, Griffin MJ et al. The validity of self-reported occupational exposures to hand-transmitted and whole-body vibration. Occup Environ Med 2000;57:237-41.

20 Walsh K, Cruddas M, Coggon D. Interaction of height and mechanical loading of the spine in the development of low-back pain. Scand J Work Environ Health 1991;17:420-4.

21 Walsh K. An epidemiological study of low back pain. MD thesis, University of Southampton, Southampton, 1992.

22 Smedley J, Egger P, Cooper C, et al. Manual handling activities and risk of low back pain in nurses. Occup Environ Med 1995;52:160-3.

23 Stata Corp. Stata statistical software: release 5.0. College Station. TX: Stata Corporation, 1997.

24 Zocchetti C, Consonni D, Bertazzi PA. Relationship between prevalence rate ratios and odds ratios in cross-sectional studies. Int J Epidemiol 1997;26:220-3

25 Griffin MJ. Handbook of human vibration. London: Academic Press, 1990.

26 International Organisation for Standardisation. Guide for the evaluation of human exposure to whole body vibration - part 1: general requirements. ISO 2631-1, 1997.

27 Office of Population Censuses and Surveys. Census 1991: Economic activity report. London: HMSO, 1993.
28 Efron B Tibshirani R. An introduction to the bootstrap. New York: Chapman and Hall, 1993.

29 Boshuizen HC, Bongers PM, Hulshof CTJ. Self-reported back pain in tractor drivers exposed to whole-body vibration. Int Arch Occup Environ Health 1990:62:109-15.

30 Brendstrup T, Biering Sorensen F. Effect of fork-lift truck driving on low-back trouble. Scand J Work Environ Health 1987;13:445-52.

31 Boshuizen HC, Bongers PM, Hulshof CTJ. Self-reported back pain in forklift truck and freight-container drivers exposed to whole-body vibration. Spine 1992;17:59-65.

32 Shelerud R. Epidemiology of occupational low back pain. Occupational Medicine: State of the Art Reviews 1998;13:1-22.

33 Hoogendoorn WE, van Poppel MNM, Bongers PM, et al. Physical workload during work and leisure time as risk factors for back pain. Scand J Work Environ Health 1999;25:387-403

34 Vingard E, Alfredsson L, Hagberg $M$, et al. To what extent do current and past physical and psychosocial occupational factors explain care-seeking for low back pain in a working population? Results from the Musculoskeletal Intervention Center-Norrtalie Study. Spine 2000;25:493-500.

35 Palmer KT, Coggon DN, Bendall HE, et al. Whole-body vibration: occupational exposures and their health effects in Great Britain. HSE CRR 233/1999. Sudbury: HSE Books, 1999.

\section{$\mathrm{ECHO}$}

\section{US occupational injury is falling haphazardly}

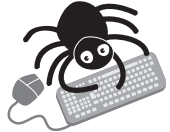

Please visit the Occupational and

Environmental Medicine website [www. occenvmed. com]

for a link to the full text of this article.
D eath rates from unintentional occupational injury in the United States have fallen 3\% a year during 1980-96, according to updated trend data. However, death from homicide at work dropped just $1 \%$ a year and is now second only to motor vehicle accidents as the leading cause of death in the job.

Death rates fell among all ages, races and in both sexes but more steeply in workers aged $<20$ than $>50$ years, in black or white workers than other races, and in males than females.

In industry death rates fell 5\% a year in electrical and gas utilities; sawmilling and agriculture; fishing, hunting, and trapping; and service occupations. In transportation the reduction was modest or static. Workers living in southern and western states benefited most, where death rates fell by $7-8 \%$ a year, probably with a change from farming, mining, wood production, and fishing into retail and technical jobs. Rates in north eastern and midwest states fell only about $2-3 \%$ a year, and rates for homicide at work rose more than sixfold.

Changes in workforce and working conditions are responsible, say analysts. Lower employment in hazardous jobs is certainly true for men, and improved safety overall and changes in some industrial processes have also contributed.

Trends for 1980 to 1986 were calculated with a Poisson model. Death rates were calculated from data of the National Traumatic Occupational Fatalities (NTOF) surveillance system in workers aged $\geqslant 16$ years in 30 occupational and 48 industrial categories. The workforce at risk was calculated from 1980 and 1990 population censuses.

A Injury Prevention 2003;9:9-14 